\title{
MAMMAPRINT: UMA ANÁLISE SOBRE A MODERNA FERRAMENTA DE AUXÍLIO NO TRATAMENTO DO CÂNCER DE MAMA
}

\author{
MAMMAPRINT: AN ANALYSIS ON THE NEW AID TOOL IN THE \\ TREATMENT OF BREAST CANCER
}

\author{
Wanessa Lobo Matos'; Maycon Willian Bachiega'; Mariana Diniz Prado Sena'; \\ Virgílio Guedes²
}

\begin{abstract}
RESUMO
Introdução: O câncer de mama é o segundo mais comum entre as mulheres, podendo ter uma evolução rápida e fatal. Nesse contexto, as novidades em tratamento e prognóstico estão cada vez mais em voga, mostrando-se eficientes, como é o caso do MammaPrint. Este teste diagnóstico, que mede a expressão dos 70 genes, analisa uma série de aspectos universais da biologia do tumor de mama e estabelece o seu risco de recidiva a fim de melhor indicar terapias adjuvantes ou neoadjuvante no tratamento do câncer de mama. Objetivo: Buscou-se fazer uma revisão das atualizações sobre o MammaPrint. Metodologia: Trata-se de um artigo de revisão cujo estudo foi feito a partir de artigos encontrados através dos descritores "mammaprint", "70-gene signature" e "câncer de mama" nos seguintes bases de dados: Pubmed e Lilacs. Após a leitura dos títulos, foram selecionados 30 artigos, sendo que 12 fizeram parte do trabalho. Conclusão: 0 MammaPrint mostrou ser uma ferramenta eficaz na avaliação de prognóstico para pacientes com câncer de mama. Porém, por se tratar de uma tecnologia nova, necessita de mais estudos para corroborar sua eficácia, aumentar sua credibilidade na área médica e seu acesso à população.

Palavras-chave: Câncer de mama. MammaPrint. Assinatura dos 70 genes. Plataforma gênica.
\end{abstract}

Citação: Matos WL, Bachiega MW, Sena MDP, Guedes VR (2017) Mammaprint: uma análise sobre a moderna ferramenta de auxílio no tratamento do câncer de mama. Revista de Patologia do Tocantins, 4(2): 10-14.

Instituição: 'Academico(a) de Medicina Universidade Federal do Tocantins, Tocantins, Brasil; ${ }^{2}$ Médico Patologista, docente - Universidade Federal do Tocantins, Tocantins, Brasil;

Autor correspondente: Wanessa Lobo Matos; wanessalobomed@gmail.com

Editor: Guedes V. R. Medicina, Universidade Federal do Tocantins, Brasil.

Publicado: 20 de junho de 2017.

Direitos Autorais: (C) 2017 Matos et al. Este é um artigo de acesso aberto que permite o uso, a distribuição e a reprodução sem restrições em qualquer meio, desde que o autor original e a fonte sejam creditados.

Conflito de interesses: os autores declararam que não existem conflitos de interesses.

\section{ABSTRACT}

Introduction: Breast cancer is the second most common among women and may have a rapid and fatal outcome. In this context, the novelties in treatment and prognosis are increasingly in vogue, proving to beefficient, as is the case of MammaPrint. This diagnostic test that measures the expression of the 70 genes analyzes a number of universal aspects of breast tumor biology and establishes the risk of tumor recurrence in order to better indicate adjuvant orn eoadjuvant therapies in thetreatment of breast cancer. Objective: We sought to review MammaPrint updates. Methods: This is a review article Whose study was based on articles found through the descriptors "mammaprint", "70-gene signature" and "breast cancer" in the following data bases: Pubmed and Lilacs. After reading the titles, 30 articles were selected and of these 12 were part of the work. Conclusion: MammaPrint has been shown to be na effective tool in the prognostic evaluation of breast cancer patients. However, because it is a new technology, it needs more studies to corroborate its effectiveness, increase its credibility in the medical areaand its Access to the population.

Keywords: Breast cancer. MammaPrint. 70-gene signature. Gene platform. 


\section{INTRODUÇÃO}

O câncer de mama é o segundo tipo de câncer mais comum entre as mulheres, sendo diagnosticado 1,2 milhões de novos casos todos os anos. De acordo com o relatório da Organização Mundial da Saúde, a incidência desta neoplasia pode aumentar em até $50 \%$ em 2020 . No Brasil, o câncer de mama representa cerca de $15 \%$ das mortes por câncer (SÁNCHEZ-FORGACH, 2016). Estilo de vida, fatores ambientais, alimentação, idade avançada, fatores reprodutivos, condições socioeconômicas, obesidade, urbanização, tabagismo, lactação, radiação ionizante e histórico familiar de câncer estão entre os fatores de risco para o desenvolvimento de câncer de mama. Aproximadamente $80 \%$ dos casos são esporádicos, causados pela acumulação progressiva de múltiplas mutações gênicas combinadas com desregulação epigenética adquiridas ao longo da vida, sendo entre 65 a 80 anos a principal faixa etária de aparecimento do tumor (CESAR, 2012).

Desde a última década, estão sendo usadas diretrizes clínico-patológicas para orientar as decisões de tratamento sistêmico adjuvante (AST) em pacientes com câncer de mama em estágio inicial; essas diretrizes baseiam-se na combinação de fatores clínico-patológicos, tais como idade, tamanho do tumor, grau, estado hormonal-receptor e estado nodal para estimar o risco de recorrência (CESAR, 2012). A maioria dos escores clínicos de avaliação de prognóstico considera apenas uma pequena proporção de pacientes como baixo risco de recorrência, portanto, sem a indicação de AST, podendo resultar num número substancial de doentes tratados com quimioterapia. Diante desse cenário diversos testes genômicos têm sido desenvolvidos para melhor predizer o desfecho clínico e determinar se vale a pena a adição de quimioterapia adjuvante à terapia endócrina, já que $50 \%$ das mulheres são tratadas com quimioterapia desnecessariamente (BEUMER, 2016).

O MammaPrint, aprovado pela Food and Drug Administration (FDA), usa os níveis de expressão dos 70 genes para medir uma série de aspectos universais da biologia do tumor de mama incluindo proliferação, angiogênese, invasão e sinalização dos receptores de estrogênio (ER), com o objetivo de determinar, com boa precisão, como o câncer vai progredir no futuro. Além disso, prediz o risco de recorrência do câncer de mama em estágio inicial, classificando os tumores em grupos que estão associados a um bom prognóstico ou a um mau prognóstico com base no risco de recorrência distante aos 5 anos e aos 10 anos. Após a análise dos 70 genes pacientes considerados de baixo risco com status de receptores hormonais positivos poderiam notadamente ser tratados por terapia hormonal como adjuvante, enquanto os pacientes designados de alto risco são mais adequados para receber uma combinação de quimioterapia e terapia hormonal em um cenário neoadjuvante. Assim o paciente tem um tratamento melhor conduzido evitando a exposição a quimioterápicos desnecessariamente (DRUKKER, 2014).

\section{MATERIAL E MÉTODOS}

O presente estudo constitui-se de uma revisão de dados baseados em publicações recentes sobre o Mammaprint, com o intuito de verificar sua validade em relação ao prognóstico e à decisão de tratamento para pacientes com câncer de mama. Para isso, realizou-se a pesquisa nos seguintes bancos de artigos: PubMed, Lilacs e o portal de periódicos da CAPES. Utilizando-se como palavraschave: MammaPrint, 70-gene signature, plataforma gênica e câncer de mama. Em Fevereiro de 2017, foram selecionados 30 artigos no Pubmed utilizando a pesquisa avançada pelo título "Mammaprint" e ano de publicação desde 2014. Desses, 15 foram selecionados pelo título e resumo e 7 fizeram parte do artigo. Também foram escolhidos 21 artigos no Pubmed pela pesquisa avançada através do título "70 genes signature". Desses, 9 foram selecionados pelo título, dos quais 6 foram selecionados pelo resumo e fizeram parte do artigo. Por fim, 01 artigo de 2012 foi selecionado pela plataforma Lilacs utilizando o prescritor "plataforma gênica".

\section{Mammaprint}

O MammaPrint é um teste baseado em tecnologia de micro-arranjos de DNA, que usa os níveis de expressão de 70 genes para avaliar o risco de recorrência de tumor em estágio inicial de câncer de mama (BEUMER, 2016). Trata-se de um marcador de prognóstico independente de fatores clínicos e patológicos convencionais, tais como tamanho do tumor, status de receptores hormonais e do status de fator de crescimento epidérmico 2 (HER2) (SÁNCHEZ-FORGACH, 2016). A assinatura dos 70 genes (MammaPrint) é realizada em tecido de tumor, que é imediatamente colocado em um preservante de RNA mensageiro (RNAm) após a operação e retirada deste. $O$ teste é adequado tanto para tecidos frescos quanto para aqueles embebidos em parafina fixados em formalina (BEUMER, 2016). Tais tecidos são mandados para o laboratório clínico na Holanda, o Agendia, onde é feito um teste histológico de coloração para verificar se a peça de fato possui um tumor. A tecnologia baseada em micro-arranjos de DNA trata-se de uma pequena superfície sólida que é dividida em milhares de minúsculas grades. Cada grade contém um DNA com um código diferente que corresponde a um gene específico. No caso do MammaPrint, trata-se de um gene de tumor mamário. Somente o RNA desse gene particular pode se ligar a essa grade particular. Micro-arranjos de DNA permitem que seja estudada a atividade de centenas ou até milhares de genes simultaneamente. O teste mede o nível de RNAm de 1.900 diferentes genes, e a expressão de 70 genes específicos é medida por seis vezes para que sejam examinados em maior detalhe. Uma vez que o câncer é causado por genes hiperativos, é essencial que se saiba qual é o seu causador, e isso pode ser determinado por intermédio do uso de micro-arranjos que comparam a atividade dos genes em células saudáveis com a atividade desses em células tumorais (CESAR, 2012).

A assinatura dos 70 genes tem sido desenvolvida em séries retrospectivas de pacientes com câncer de mama para prever o risco de metástases distantes. O estudo microARRAyprognoSTics-in-breast-cancer (RASTER) foi o primeiro estudo projetado para avaliar prospectivamente o desempenho da assinatura de 70 genes. 0 desenho do estudo selecionou 812 pacientes do sexo feminino de 16 hospitais na Holanda. Desses, 427 pacientes foram de pós-operatórios, e para eles uma assinatura dos 70-genes foi obtida. Todos os pacientes tinham entre 18 e 61 anos de idade, com diagnóstico de 
adenocarcinoma invasivo unilateral, unifocal e invasivo primário da mama, confirmado histologicamente. Todos os pacientes foram primariamente tratados cirurgicamente com cirurgia de conservação da mama ou mastectomia. As decisões sobre o Tratamento Sistêmico Adjuvante (AST) incluindo quimioterapia e/ou terapia endócrina, nesse estudo, foram baseadas nas diretrizes nacionais holandesas de 2004, na assinatura dos 70 genes e nas preferências dos médicos e pacientes. Os resultados desse estudo sugeriram que é seguro reter a quimioterapia em grupos de pacientes de baixo risco baseados no MammaPrint, confirmando a capacidade do teste para estratificar os pacientes com precisão em terapias de tratamento apropriadas (DRUKKER, 2014).

\section{Avaliação de prognóstico}

Desde 2004, a assinatura dos 70 genes tem sido utilizada por mais de 90.000 pacientes para determinar o risco de recorrência da doença, portanto, determinando o seu prognóstico (BEUMER, 2016).

Estudos clínicos demonstraram o valor prognóstico do MammaPrint no câncer de mama com linfonodos negativos ou positivos, para mulheres diagnosticadas em todas as idades e independentemente do grau patológico, status de receptor de estrogênio ou expressão HER2.

Como já apresentado, o estudo RASTER forneceu a primeira evidência prospectiva de utilidade clínica para MammaPrint. Nesse estudo, cerca de $50 \%$ das pacientes foram consideradas de baixo risco para a recorrência do câncer de mama através do ensaio MammaPrint, e a taxa de sobrevivência sem metástase à distância em cinco anos para essas pacientes foi de $96,1 \%$. O estudo ainda mostrou uma taxa de sobrevivência livre de metástases de 98,9\% em 5 anos em pacientes com risco clinicamente alto, com base em parâmetros clínicos padrões, porém com status de baixo risco, baseado na assinatura dos 70 genes, sem que houvesse 0 recebimento de quimioterapia adjuvante (BEUMER, 2016).

Outros estudos desenvolvidos também têm mostrado resultados satisfatórios quanto à utilização do MammaPrint. Um ensaio clínico randomizado realizado na Europa, com 6693 mulheres com diagnóstico de câncer de mama em estágio inicial, mostrou que as pacientes com alto risco clínico e baixo risco genômico para recidiva, o recebimento de nenhuma quimioterapia com base apenas no MammaPrint levou a uma taxa de 5 anos de sobrevivência sem metástase à distância 1,5 pontos percentuais menor do que a taxa com quimioterapia (CARDOSO, 2016).

Para o carcinoma lobular invasivo (CLI), que corresponde ao segundo tipo de câncer de mama mais prevalente com base em critérios histológicos - atrás apenas do carcinoma ductal invasivo, os resultados de um estudo validaram o MammaPrint como um fator independente de prognóstico, considerando casos de $\mathrm{CLI}$ em estágio inicial (BEUMER, 2016).

\section{Impacto em longo prazo}

A maioria das metanálises de pacientes com câncer de mama mostram que a quimioterapia adjuvante reduz a taxa de recidiva quase que exclusivamente nos primeiros 5 anos, e que por isso grande parte dos estudos analisa esse intervalo de tempo. Objetivando avaliar o valor prognóstico de câncer de mama em estágio inicial após 5 anos utilizando a assinatura dos 70 genes, foi realizado um estudo de coorte consecutiva de 295 pacientes com neoplasia de mama diagnosticados no Instituto Holandês do Câncer entre 1984 e 1995. Os pacientes tiveram suas amostras de tumor descongeladas e processadas para análise de acordo com a plataforma gênica escolhida até 2013. Nesse estudo, a assinatura dos 70 genes possuiu o maior valor prognóstico para a sobrevida livre de metástases à distância em longo prazo (SLMD) e a sobrevivência global (SG) nos primeiros 5 anos. $O$ valor prognóstico significativo por intervalo de 5 anos para SG permaneceu a partir de 5 anos após o diagnóstico e tornou-se menor apenas após 15 anos (DRUKKER, 2014).

Foi possível supor que as probabilidades de sobrevivência desta coorte, se diagnosticada hoje, seria ainda melhor do que o mostrado aqui, devido a melhores métodos de detecção precoce e de tratamento. Deve-se destacar ainda que os pacientes incluídos eram todos menores de 53 anos, que tendem a ter um pior prognóstico em relação aos pacientes diagnosticados em idade mais avançada. Essa atualização mostra que o MammaPrint, em longo prazo, tem bom valor prognóstico em pacientes com 53 anos de idade com estágio I e II de câncer de mama, em até 25 anos após o diagnóstico (DRUKKER, 2014).

\section{Comparação entre escores clínicos diferentes na avaliação de prognóstico}

Existem inúmeros escores clínicos que são utilizados para avaliação de prognóstico do tratamento em pacientes com câncer de mama associados ao MammaPrint, dentre eles, o PREDICT plus, o Adjvante Online e as diretrizes nacionais holandesas de 2004 e 2012. (DRUKKER, 2014).

O estudo RASTER revelou que dentre todos os algoritmos de previsão de risco clínico utilizados, a ferramenta online PREDICT plus e as diretrizes nacionais holandesas de 2012 resultaram nas melhores estimativas de risco. De forma similar, ambas as ferramentas utilizam o status HER 2 do tumor. O que as diferencia é a utilização do método de detecção, feito apenas pelo PREDICT plus. (DRUKKER, 2014).

O Adjuvante Online (AOL) mostrou a pior previsão de risco antes e após a adição de 70-gene assinatura. Isso pode ser explicado pelo fato de que esta diretriz não incorpora o status de HER2. Quando utilizado exclusivamente a assinatura de 70 genes, o número de pacientes com alto risco de recorrência que são elegíveis para quimioterapia adjuvante seria reduzido em $20 \%$ em comparação com AOL isolado (DRUKKER, 2014).

A única ferramenta que foi acertadamente capaz de selecionar pacientes de alto risco para recorrência de câncer de mama, dentre os pacientes considerados de baixo risco pela assinatura genética, foi a online PREDICT plus. No entanto, neste subgrupo o número de doentes $(n=17)$ foi demasiado baixo para tirar conclusões firmes. Uma coorte maior é necessária para avaliar o valor prognóstico adicional da assinatura de 70 genes para a ferramenta PREDICT plus. É fato que o desenho do estudo fornece uma ótima reflexão da prática clínica diária, porém mecanismos sutis de seleção podem estar presentes e podem ter influenciado os resultados. Outra possível limitação é que todas as 
ferramentas e diretrizes clínicas incluídas em nossas análises usam definições ligeiramente diferentes de alto e baixo risco. Essas diferenças criam um grupo adicional de pacientes para os quais as diretrizes clínicas fornecem estimativas de risco discordantes. Além disso, algumas diretrizes baseiam sua avaliação de risco em probabilidades de sobrevivência em 5 anos, enquanto outras em probabilidades de sobrevivência em 10 anos. Deve-se ter em mente que os resultados deste estudo são baseados em um caso de mistura relativamente jovem (média de 61 anos) de pacientes com câncer de mama. Finalmente, a revisão da patologia central pode ter alterado os resultados, uma vez que um relatório anterior mostrou que, para $8 \%$ dos pacientes, as estimativas de risco de $\mathrm{AOL}$ mudariam com base na revisão da patologia. Existem poucos estudos que comparam a diferença da efetividade entre os scores clínicos, sendo necessário mais estudo para essa elucidação. (DRUKKER, 2014).

Essa diferença entre os scores clínicos que são utilizados juntamente com o MammaPrint para predizer o prognóstico é extremamente relevante. Doze oncologistas avaliaram 37 casos de câncer de mama (cT1-3NOM0), estimaram seu risco de recorrência (alta ou baixa) e deram uma recomendação para AST. Os casos foram apresentados em dois questionários escritos enviados com 4 semanas de intervalo. Apenas o segundo questionário incluía o resultado da assinatura de 70 genes. (DRUKKER, 2014).

Apenas um nível moderado de concordância, tanto para as estimativas quanto para as decisões de tratamento, foi observado entre os oncologistas quando utilizaram os fatores clínico-patológicos usados nas diretrizes atuais, como idade, tamanho do tumor, grau e status do receptor hormonal, devido aos diferentes protocolos clínicos presentes. Globalmente, a redução da proporção de pacientes de alto risco de $7,4 \%$ e redução de $12,2 \%$ no uso de quimioterapia, foram observadas nesta seleção de casos. As taxas de especificidade previamente relatadas da assinatura de 70 genes $(0,56)$ são superiores à $\operatorname{AOL}(0,53)$ e St. Gallen $(0,10)$ aos 5 anos de seguimento num conjunto de dados de 70 genes de validação de assinaturas de doentes não tratados com ER positivo e câncer de mama linfonodo negativo. (DRUKKER, 2014).

\section{Receio sobre o "novo"}

Após a aprovação do MammaPrint pelo FDA (Food and Drug Administration) em 2008, a utilização de testes diagnósticos multigênicos para orientar o tratamento do câncer aumentou dramaticamente nos últimos anos (BEUMER, 2016). Contudo, por tratar-se de uma ferramenta nova, que influencia a conduta de profissionais experientes sobre tratamento, praticamente excluindo o uso de critérios clínicos tradicionais, alguns desses profissionais ainda têm mostrado certo receio sobre o uso da assinatura dos 70 genes (EXNER, 2014).

Um estudo, que objetivou explorar o efeito do perfil de risco molecular baseado no MammaPrint sobre a tomada de decisão de uma equipe multidisciplinar, evidenciou o receio de uma equipe multidisciplinar sobre o uso do teste genômico. Nesse ensaio, o foco principal foi registrar mudanças na tomada de decisão atribuída à discordância de risco entre o perfil de risco clínico e molecular em casos de câncer de mama em estágio inicial. Um achado importante foi exatamente a alta taxa de discordância: das 75 mulheres incluídas no estudo, 29 (39\%) apresentaram discordância entre seu perfil clínico e molecular. Mais de dois terços dos casos discordantes resultaram em diminuição do risco e subseqüentemente levaram a equipe multidisciplinar a alterar suas decisões sobre o tratamento, optando por abandonar a quimioterapia. Curiosamente, a equipe mudou sua decisão em apenas metade desses casos $(n=14)$. Foram sugeridas três razões principais para esta conclusão:

1. Várias mulheres com indicações claras para quimioterapia foram incluídas no estudo e, portanto, a equipe não omitiu a quimioterapia das recomendações nestes cinco casos.

2. Quatro mulheres consideradas de baixo risco pela equipe multidisciplinar (e em retrospecto, de fato, nenhuma indicação relativa para quimioterapia) apresentaram assinaturas moleculares de alto risco. $O$ valor preditivo do MammaPrint quanto ao benefício do quimioterapia era questionável e esta foi a principal razão para não adicionar tratamento citotóxico nestes pacientes.

3. Finalmente, permaneceu um grupo de seis mulheres onde, apesar da validação prognóstica adequada do teste e de um perfil molecular de baixo risco, a equipe recomendou o tratamento quimioterápico (EXNER, 2014).

\section{CONCLUSÃO}

Nos últimos anos, o desenvolvimento de novas técnicas de diagnóstico, avaliação de prognóstico e escolha de tratamento para câncer de mama tem se mostrado promissor, principalmente por levar em conta as características específicas do tumor e de cada paciente. A evolução nos métodos diagnósticos se faz importante uma vez que o câncer de mama possui uma evolução muito rápida e potencialmente fatal.

Visando a otimização do tratamento, o acréscimo de plataformas gênicas na tomada de decisão frente à terapia hormonal e quimioterapia tem se mostrado de grande relevância. A plataforma gênica de destaque e tema desse artigo é o MammaPrint.

Os inúmeros estudos mostram que a utilização da assinatura dos 70 genes é eficaz para determinar o risco de recorrência de câncer de mama em estágio inicial. Portanto, considera-se uma ferramenta vital para a tomada de decisão de quimioterapia adjuvante para um paciente em particular, evitando tratamentos desnecessários, melhorando a qualidade de vida e reduzindo os custos. Tudo isso faz parte do que hoje é considerada medicina personalizada, o que implica diretamente na redução da taxa de mortalidade desta doença.

Apesar dos bons resultados da utilização do MammaPrint, é válido ressaltar que essa ferramenta ainda não está disponível para todos os pacientes. Com um custo elevado, há uma limitação de cunho econômico para alguns candidatos ao uso da plataforma gênica. Sabe-se que nos grupos de mulheres com câncer de mama precoce, sem recursos para realizar o teste multigênico, ainda são usados critérios tradicionais para a decisão de receber ou não quimioterapia. Frente a esse impasse, acredita-se que a implementação do uso do MammaPrint em sistemas nacionais de saúde seja de grande importância, pois reduziria os gastos 
públicos com internações para tratamentos quimioterápicos e, principalmente, evitaria a exposição desnecessária de centenas de mulheres a esse tipo de terapia.

Além disso, vale recordar que há certo ceticismo de alguns médicos em relação ao prognóstico molecular, revelando a necessidade de mais estudos sobre o assunto.

\section{REFERÊNCIAS}

1- BEUMER, I. et al. Equivalence of MammaPrint array types in clinical trials and diagnostics. Breast Cancer Research and Treatment. Vol 156, p. 279-287, March 2016

2- BEUMER, I. et al. Prognostic value of Mammaprint ${ }^{\circledR}$ in invasive lobular breast cancer. Biomarker Insights. Vol 11, p. 139-146, October 2016.

3- CARDOSO, F. et al. 70-gene signature as an aid to treatment decisions in early-stage breast cancer. The New England Journal of Medicine. Vol 375, p.717729, August 2016.

4- CESAR, P. G. C. et al. Utilização de plataforma gênica no prognóstico do câncer de mama. Arquivos Brasileiros de Ciências da Saúde. Vol 37, No 03, p. 154-161, Set/Dez 2012.
5- DRUKKER, C. A. et al. Long-term impact of the 70gene signature on breast cancer outcome. Breast Cancer Research Treatment. Vol 143, n³, p.587-592, Feb 2014

6- DRUKKER, C. A. et al. Optimized outcome prediction in breast cancer by combining the 70-gene signature with clinical risk prediction algorithms. Breast Cancer Research and Treatment. Vol 145, $n^{\circ} 3$ p. 697-705, April 2014.

7- DRUKKER, C. A. et al. Risk estimations and treatment decisions in early stage breast cancer: agremment among oncologists and the impact of the 70-gene signature. European Journal of Cancer. Vol 50, $n^{\circ} 6 \mathrm{p}$ 1045-1054, April 2014.

8- EXNER, E. et al. The multigene signature MammaPrint impacts on multidisciplinar team decisions in ER +, HER2 - early breast cancer. British Journal of Cancer. Vol 111, n5, p.3261-7, August 2014.

9- SÁNCHEZ-FORGACH, E. R. et al. Validación y aplicación clínica de MammaPrint ${ }^{\circledR}$ en pacientes con cáncer de mama. Cirurgía y Cirujanos, Vol 283, Octubre 2016. 